\title{
Decadal-Scale Modulation of Atmospheric Circulation Change at the Onset of the Western North Pacific Summer Monsoon
}

\author{
Tomohiko Tomita $^{1,2}$, Tsuyoshi Yamaura ${ }^{3}$, and Yuta Kuwazuru ${ }^{1}$ \\ ${ }^{1}$ Graduate School of Science and Technology, Kumamoto University, Kumamoto, Japan \\ ${ }^{2}$ Research Institute for Global Change, JAMSTEC, Yokohama, Japan \\ ${ }^{3}$ Advanced Institute for Computational Science, RIKEN, Kobe, Japan
}

\begin{abstract}
Decadal-scale modulation (DSM) appears in the atmospheric circulation change around the onset (July 20) of the western North Pacific summer monsoon (WNPSM). This work examined the DSM associated with the onset precipitation increase (OPI), using global reanalysis datasets from 1979 to 2010 (32 years). The years 1985-1993 had positive decadal anomalies, and the onset precipitation increased with the development of specific meridional circulation similar to the Pacific-Japan pattern. In the subsequent negative term of the years 1994-2000, the atmospheric circulation change was distinguished by a smaller OPI, southwestward extension of the WNPSM, and an anomalous wave train emanating northeastward from the Philippines. The patterns in the following positive decadal term of the years 2001-2007 were similar to those in the preceding negative term but with opposite signs. These changes in the DSM were coherent with decadal sea surface temperature (SST) anomalies before the onset around the region of $28-29^{\circ} \mathrm{C}$ in SST in the western North Pacific due to vertical instability under the trade wind inversion.
\end{abstract}

(Citation: Tomita, T., T. Yamaura, and Y. Kuwazuru, 2013: Decadal-scale modulation of atmospheric circulation change at the onset of the western North Pacific summer monsoon. SOLA, $\mathbf{9}$, 161-165, doi:10.2151/sola.2013-036)

\section{Introduction}

The western North Pacific summer monsoon (WNPSM) is a specific boreal summer monsoon appearing over the ocean around $\left(150^{\circ} \mathrm{E}, 20^{\circ} \mathrm{N}\right)$ (Fig. 1a), while other monsoons are prevalent in and around the boundary between the ocean and the continent. The WNPSM is characterized by precipitation and westerly or southerly winds that increase rapidly in late July (Fig. 1). We refer to the increase in precipitation as the onset precipitation increase (OPI) of the WNPSM (Fig. 1b). The onset of the WNPSM, whose mean date is July 20 (Fig. 1b), seems to be fixed by so-called onset disturbances, i.e., the northward movement of intraseasonal oscillations in the western North Pacific (WNP) (Wu and Wang 2000) or the westward movement of upper cold lows from the mid-Pacific trough (Sato et al. 2005). The WNPSM gradually weakens from October to November (Wang and LinHo 2002).

Using data from 1980 to 1989 (10 years), Ueda et al. (1995) found that the onset of WNPSM was concurrent with the occurrence of specific large-scale meridional circulations in the WNP similar to the Pacific-Japan (PJ) pattern (Fig. 1a; Nitta 1989), which induces a northward shift of the Baiu front, corresponding to the end of the Baiu season in Japan (Fig. 1). On the other hand, using data over a longer period from 1979 to 2001 (23 years), Suzuki and Hoskins (2009) discussed that the equivalent barotropic Rossby waves propagating over the Eurasian continent could also bring about the end of the Baiu season. These differences might be due to the time spans of data employed. That is, the

Corresponding author: Tomohiko Tomita, Graduate School of Science and Technology, Kumamoto University, 2-39-1 Kurokami, Kumamoto 8608555, Japan. E-mail: tomita@sci.kumamoto-u.ac.jp. (C)2013, the Meteorological Society of Japan.

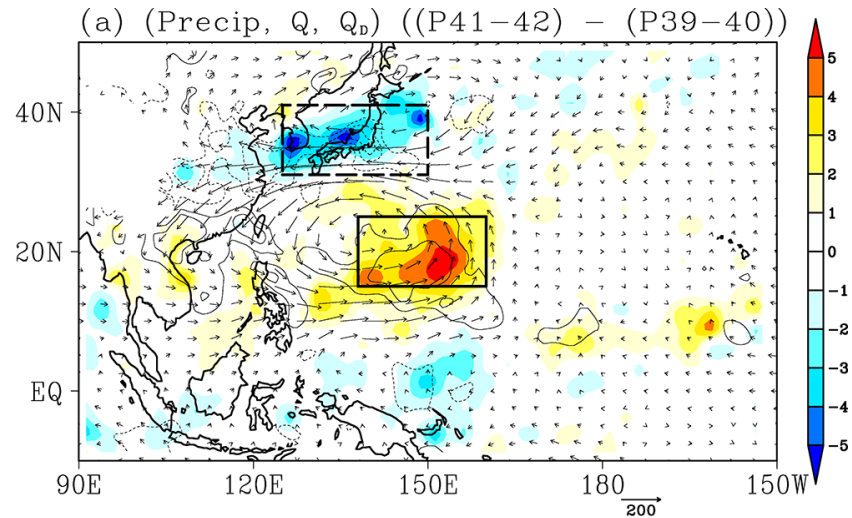

(b) Precipitation time series date

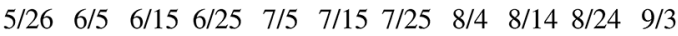

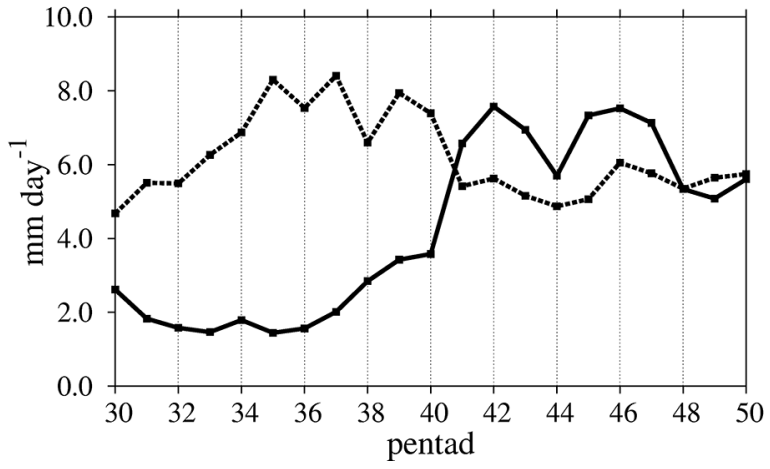

Fig. 1 (a) Differences in the precipitation rate $\left(\mathrm{mm} \mathrm{day}^{-1}\right.$; color), vertically integrated water vapor flux $\left(\mathbf{Q} ; \mathrm{kg} \mathrm{m}^{-1} \mathrm{~s}^{-1}\right.$; vector), and divergence of $\mathbf{Q}$ $\left(\mathrm{Q}_{\mathrm{D}} ; \mathrm{kg} \mathrm{m}^{-2} \mathrm{~s}^{-1}\right.$; contour) between the means of before (P39-40) and after (P41-42) the onset of the WNPSM [(P41-42) - (P39-40)]. These were estimated from the climatological mean data from 1979 to 2010 (32 years). The color scale (scale vector) is on the right (bottom). The contour interval is $2.0 \times 10^{-5} \mathrm{~kg} \mathrm{~m}^{-2} \mathrm{~s}^{-1}$, where solid (dotted) lines indicate convergence (divergence), and the zero lines are omitted for brevity. (b) Climatological time variations of the areal-mean precipitation rate in the WNPSM $\left(138^{\circ} \mathrm{E}-160^{\circ} \mathrm{E}, 15^{\circ} \mathrm{N}-25^{\circ} \mathrm{N}\right.$; solid line) and the Baiu $\left(125^{\circ} \mathrm{E}-150^{\circ} \mathrm{E}\right.$, $31^{\circ} \mathrm{N}-41^{\circ} \mathrm{N}$; dotted line) regions. These two regions are indicated by solid- and dotted-line squares in (a).

difference might reflect the decadal-scale modulation (DSM) in atmospheric circulation change around the onset of the WNPSM. This work examines this hypothesis. On the interannual time scale, it is known that the El Niño/Southern Oscillation modifies the onset atmospheric circulations (Ueda et al. 1995; Wu and Wang 2000; Chou et al. 2003).

The rest of this paper is arranged as follows. Section 2 describes the data used in this work. Section 3 indicates the DSM of OPI in the WNPSM and the associated atmospheric circulation change. The precursors of OPI and the change in DSM are examined in the planetary boundary layer (PBL) in Section 4. Finally, Section 5 gives a summary with some discussions. 


\section{Data}

This work makes use of two datasets. The first is the Global Precipitation Climatology Project (GPCP) dataset for precipitation rate with a unit, $\mathrm{mm}^{-1} \mathrm{y}^{-1}$ (Adler et al. 2003). This dataset covers the period 1979-2010 (32 years) with a 5-day mean interval, that is, a temporal resolution of 73 pentads per year, and with a horizontal resolution of $2.5^{\circ} \times 2.5^{\circ}$ across the globe. The second is the Japanese reanalysis (JRA) dataset for all other parameters including sea surface temperature (SST; Onogi et al. 2007). This dataset covers the period 1979-2010 (32 years) with 6-hourly temporal resolution (four times a day), and with a horizontal resolution of $1.25^{\circ} \times 1.25^{\circ}$ across the globe for 23 vertical layers. The finer horizontal resolution of $1.125^{\circ} \times 1.125^{\circ}$ is available for the surface data. We compiled this dataset to have a 5-day mean interval like the dataset of GPCP. The upper axis of Fig. $1 \mathrm{~b}$ indicates the first day of each 5-day average. The specific 5-day bin is indicated by a combination of $\mathrm{P}$ and the pentad number, e.g., $\mathrm{P} 40$.

In this work, interannual anomaly is defined as the difference from a regression line of the yearly time series of 32 years. That is, both the long-term mean and the linear trend are removed for the anomalies (cf. Fig. 2).

\section{DSM of OPI in the WNPSM and the related atmospheric circulation change}

We first present the time series of the interannual OPI anomaly, where OPI is defined as the precipitation rate difference between the means of P39-40 and P41-42 (latter - former) (Fig. $1 \mathrm{~b}$ ) in a solid-line square in Fig. 1a (Fig. 2; solid line with filled circles). This time series obviously shows DSM. To objectively identify the DSM, harmonic analysis was applied to this 32-year (1979-2010) time series. Then, the sum of the harmonics of wave numbers 1 to 3 , which involves periods longer than 11 years, was identified as the DSM. On the basis of this smoothed time series (Fig. 2; broken line with open circles), the positive and negative terms of the DSM were determined, i.e., 1985-1993 was positive (Term 1), 1994-2000 was negative (Term 2), and 2001-2007 was positive (Term 3), where positive (negative) implies a larger (smaller) OPI than normal. The terms at both ends of the time series were not considered.

The related atmospheric circulation change around the onset of the WNPSM is diagnosed through composite analysis based on the three terms of the DSM (Terms 1-3). In Term 1 (Fig. 3a), the positive anomalies of the OPI extended in the zonal direction along $20^{\circ} \mathrm{N}$ in the WNP, which enhanced the climatological circulation change at the onset (Fig. 1a). The decrease in precipitation at the end of Baiu season was concurrently large in a zonal region near Japan. The negative and positive anomalies also extended zonally at latitudes below $10^{\circ} \mathrm{N}$, although the distribution was

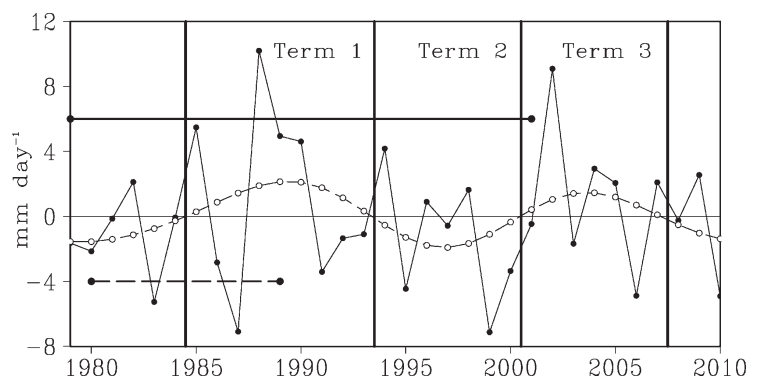

Fig. 2 Time series of detrended anomalies for the OPI of WNPSM [(P4142) - (P39-40); solid line with filled circles]. The broken line with open circles indicates the sum of harmonics with periods longer than 11 years. On the basis of this smoothed time series, the three DSM terms were determined, i.e., 1985-1993 (Term 1), 1994-2000 (Term 2), and 2001-2007 (Term 3). The horizontal solid (dashed) line indicates the length of data used by Suzuki and Hoskins (2009) (Ueda et al. (1995)). inconsistent with that in the climatology (Fig. 1a).

In Term 2 (Fig. 3b), the OPI decreased, and the region of WNPSM appeared to extend westward or southwestward. The PJlike pattern shown in the climatological circulation change (Fig. 1a) was deformed at latitudes higher than $20^{\circ} \mathrm{N}$ in the WNP, while the climatology was enhanced at latitudes below $20^{\circ} \mathrm{N}$. The differences between Figs. $3 \mathrm{a}$ and $3 \mathrm{~b}$ are reminiscent of the differences between the findings of Ueda et al. (1995) and Suzuki and Hoskins (2009). The spatial pattern shown in Term 3 (Fig. 3c) was similar to that in Term 2 (Fig. 3b), but with opposite signs. The tilting of anomalies from northwest to southeast around the Philippines was larger in Term 3 (Fig. 3c) than in Term 2 (Fig. 3b).

The corresponding DSM anomalies were also examined using geopotential height at $850 \mathrm{hPa}\left(\mathrm{Z}_{850}\right.$; color $)$ and wave activity fluxes (WAFs; vector) at this height (Fig. 4). The WAFs are useful to diagnose the direction and strength of the energy propagation of stationary Rossby waves (Takaya and Nakamura, 2001). In Term 1 (Fig. 4a), the PJ-like pattern was prominent in the WNP

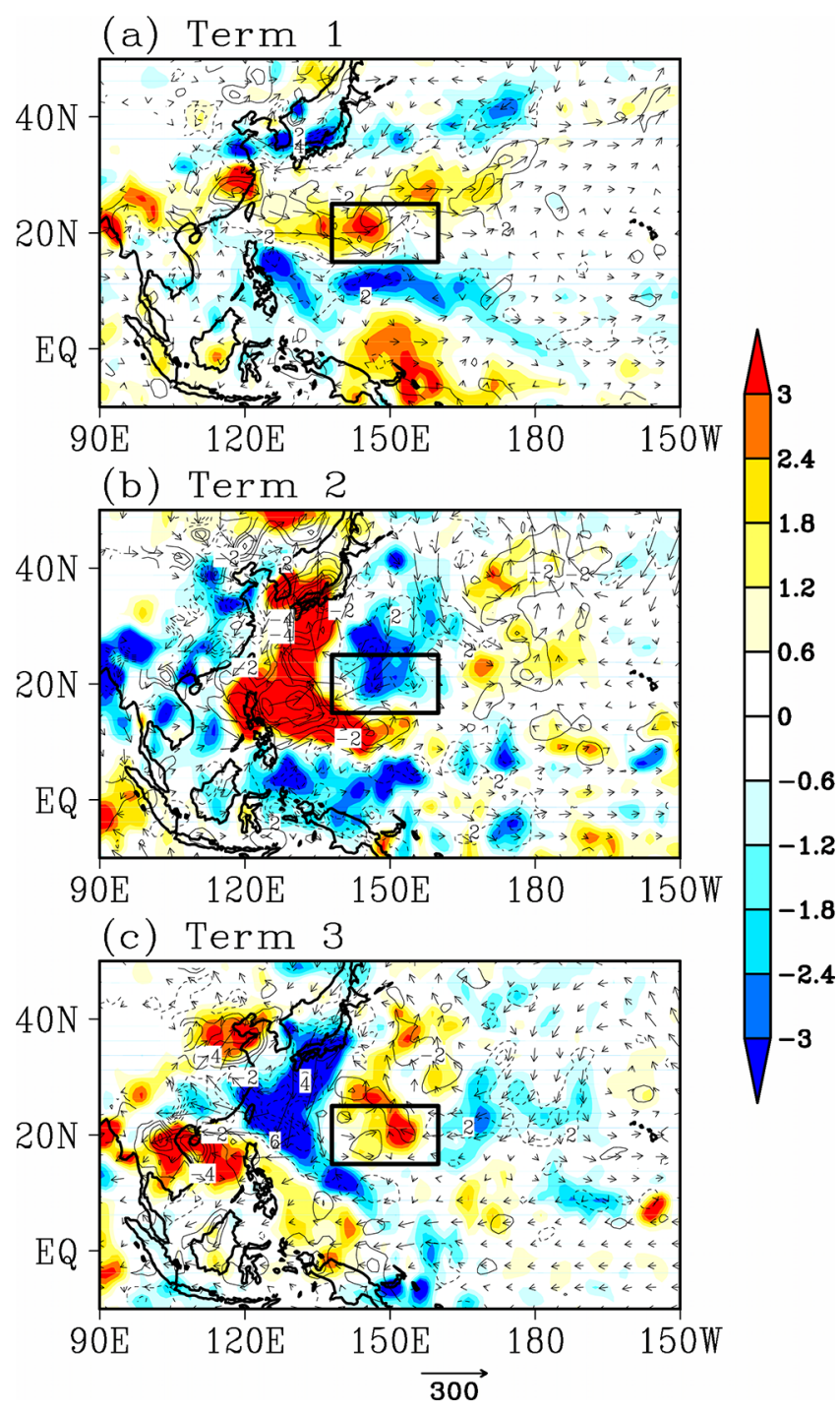

Fig. 3 Detrended anomalies of the difference between P39-40 and P41-42 [(P41-42) - (P39-40)], that is, before and after the onset of the WNPSM (Fig. 1), for the precipitation rate ( $\mathrm{mm} \mathrm{day}^{-1}$; color), $\mathbf{Q}\left(\mathrm{kg} \mathrm{m}^{-1} \mathrm{~s}^{-1}\right.$; vector), and $\mathrm{Q}_{\mathrm{D}}\left(\mathrm{kg} \mathrm{m}^{-2} \mathrm{~s}^{-1}\right.$; contour) in (a) Terms 1, (b) 2, and (c) 3. The common color scale (scale vector) is on the right (bottom). The contour interval is 2.0 $\times 10^{-5} \mathrm{~kg} \mathrm{~m}^{-2} \mathrm{~s}^{-1}$ for $\mathrm{Q}_{\mathrm{D}}$, where the solid (dotted) lines indicate anomalous convergence (divergence), and the zero lines are omitted for brevity. The rectangle $\left(138^{\circ} \mathrm{E}-160^{\circ} \mathrm{E}, 15^{\circ} \mathrm{N}-25^{\circ} \mathrm{N}\right)$ in each panel indicates the region where the WNPSM is active (Fig. 1a). 
with northward WAF anomalies emanating from the tropics. This is also supported by the pattern seen in the precipitation anomalies (Fig. 3a), indicating anomalous diabatic heating by latent heat. An arched wave train was observed in the $Z_{850}$ anomalies with anomalous eastward WAFs along the Sea of Okhotsk, the Bering Sea, and the Gulf of Alaska.

In Term 2 (Fig. 4b), a larger and stronger wave train appeared in the North Pacific extending from the Philippine Sea to western North America. The WAFs were again eastward from Japan. To the west of $180^{\circ}$ in longitude, anomalous diabatic heating with precipitation anomalies in the WNP (Fig. 3b) corresponded well to the $\mathrm{Z}_{850}$ and WAF anomalies (Fig. 4b) with a specific phase difference. The $Z_{850}$ anomalies in the northeastern part of China suggest that the stationary Rossby waves over Eurasia contributed to the modification of the northward shift of the Baiu front, as Suzuki and Hoskins (2009) suggested. A similar pattern was observed in Term 3 in the $Z_{850}$ anomaly, but with the opposite sign and smaller amplitude (Fig. 4c). Anomalous WAFs were also small and not continuous along the wave train. The PJ-like pattern was deformed in both Terms 2 and 3 .

It should be noted that there were large differences between the patterns in Terms 1 and 3 (Figs. 3a and 3c, 4a and 4c), although these terms were both positive (Fig. 2). In particular, the differences were meaningful in the Philippine Sea, the East China Sea, and the northeastern part of China. The climatologies, or decadal-scale means, in atmospheric circulation change at the onset of the WNPSM, which are estimated as the sum of Figs. 1a and 3, were less recursive over the 32 years from 1979 to 2010 .

\section{(a) Term 1}
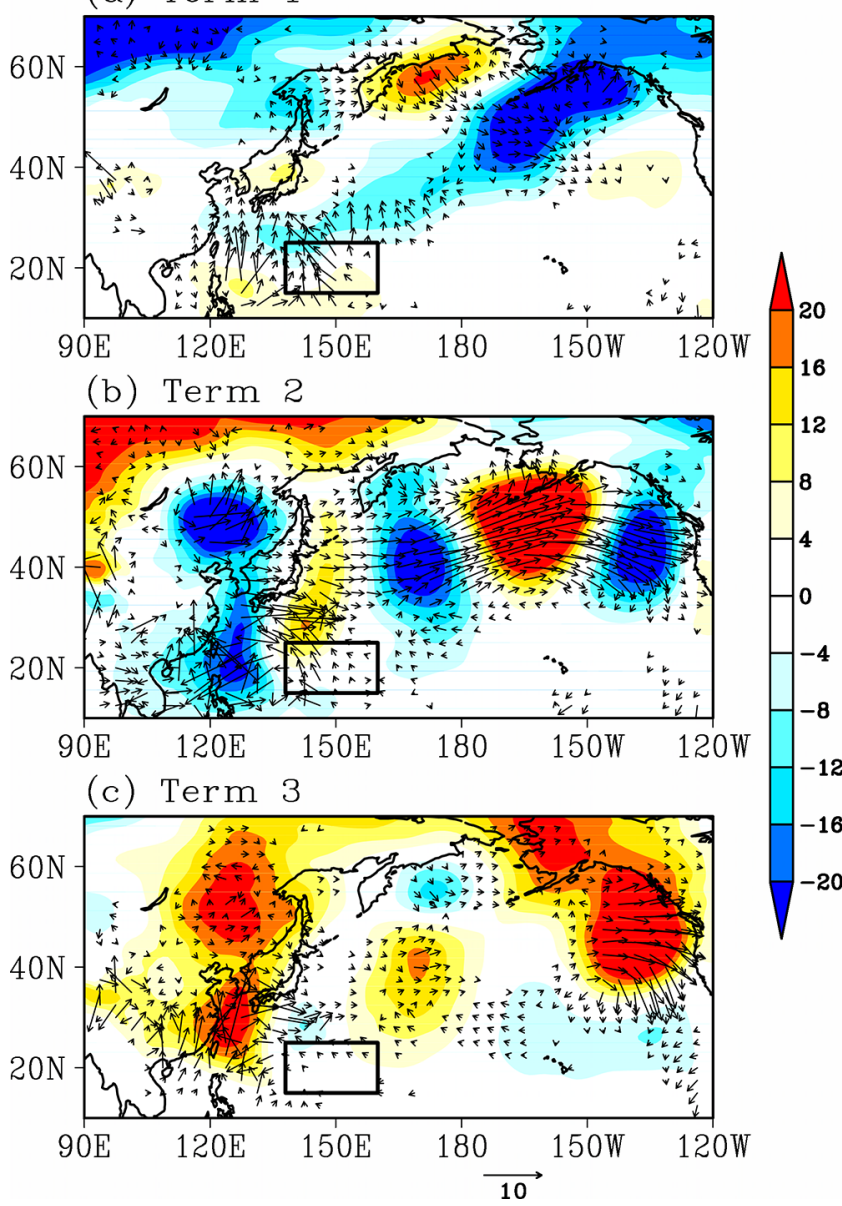

Fig. 4 As in Fig. 3 but for $Z_{850}$ (gpm; color) and WAF at $850 \mathrm{hPa}\left(\mathrm{m}^{2} \mathrm{~s}^{-2}\right.$; vector) in (a) Terms 1 , (b) 2 , and (c) 3. The common color scale (scale vector) is shown on the right (bottom).

\section{Precursors leading the DSM of OPI in the WNPSM}

Because of the long time scale, the DSM of OPI was likely driven by oceanic variations. In fact, many researchers have discussed the effects of SST anomalies (SSTAs) on the interannual variability (e.g., Ueda et al. 1995; Wu and Wang 2001; Wu 2002). To reveal the precursors of OPI in the DSM, we first examined the decadal-scale SSTAs in P37-40 before the onset (Fig. 5).

In the three DSM terms (Terms 1-3), coherent SSTAs appeared off Japan, around the Philippines, and in the central tropical Pacific (Fig. 5). Specific SSTAs were also present along $20^{\circ} \mathrm{N}$ near the region of the WNPSM. In Terms 2 (Fig. 5b) and 3 (Fig. 5c), the spatial patterns of the SSTAs were particularly similar to each other but with opposite signs. This similarity supports the idea that the decadal-scale oceanic variations systematically modulated the atmospheric circulation change at the onset of the WNPSM (Figs. 3, 4), although the spatial pattern of Term 1 (Fig. 5a) was slightly similar to that of Term 3 (Fig. 5c). The difference in SSTA between Terms 1 (Fig. 5a) and 3 (Fig. 5c) might cause

(a) Term 1
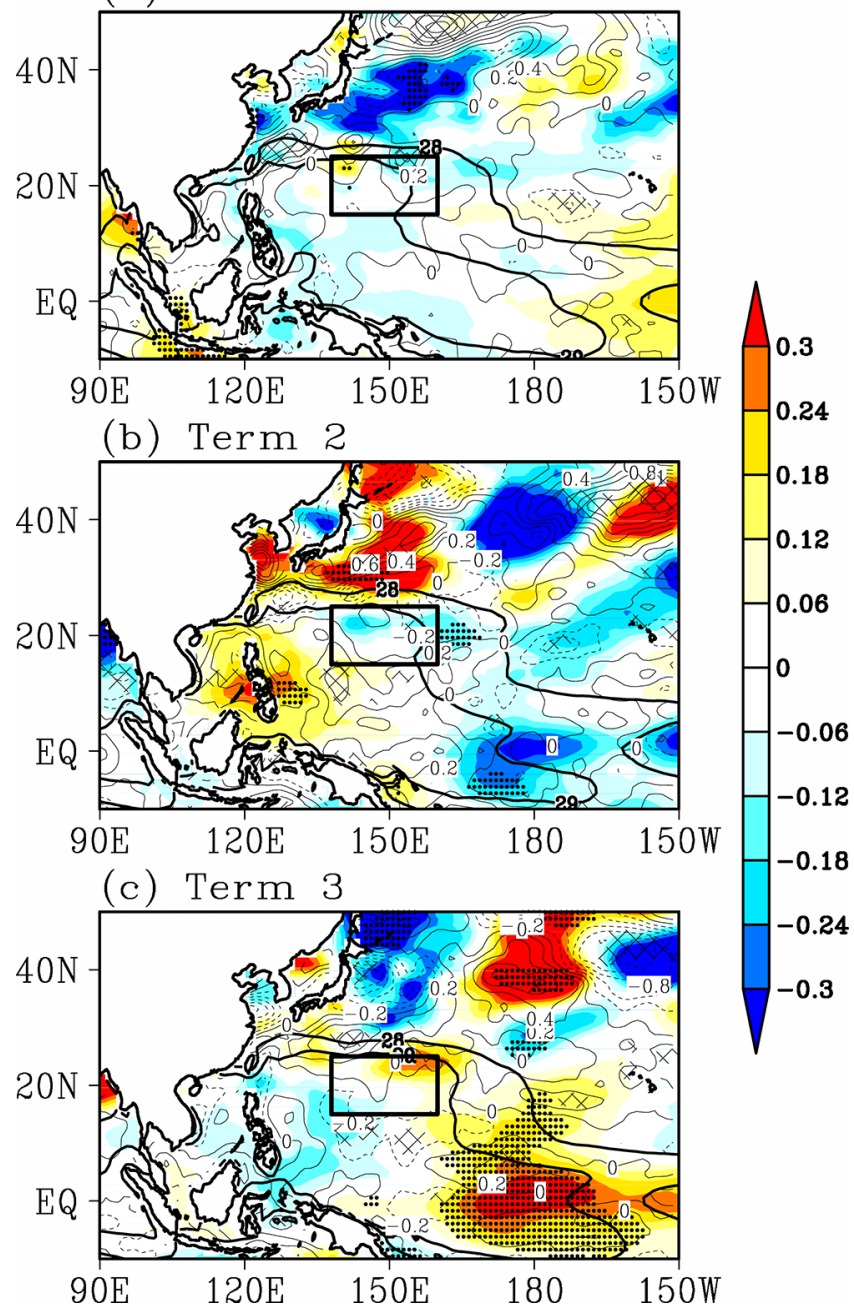

Fig. 5 Lines of $28^{\circ} \mathrm{C}$ and $29^{\circ} \mathrm{C}$ in SST (thick contour) and the SSTAs $\left({ }^{\circ} \mathrm{C}\right.$; color) in P37-40 before the onset of the WNPSM (Fig. 1b), in (a) Terms 1 , (b) 2, and (c) 3. The common color scale is on the right. The detrended anomalies of $-d \theta e /\left.d z\right|_{\mathrm{PBL}}\left(\mathrm{K} \mathrm{km}^{-1}\right.$; thin contour), which were estimated in the lower troposphere up to $850 \mathrm{hPa}$, are superimposed on each panel. The solid (dotted) contours indicate anomalous instability (stability). Black-dot (cross-line) hatching indicates the regions where anomalies are significant at the $90 \%$ level for SST $\left(-d \theta e /\left.d z\right|_{\mathrm{PBL}}\right)$. 
the difference in atmospheric circulation change shown in Figs. 3,4 .

Convective instability in the PBL, defined as the vertical gradient $\left(-d \theta e /\left.d z\right|_{\mathrm{PBL}}\right)$ of equivalent potential temperature $(\theta e)$, is useful to diagnose the potential for large-scale convection (e.g., $\mathrm{Wu}$ and Wang 2000). We examined the anomalies in $-d \theta e /\left.d z\right|_{\mathrm{PBL}}$ during P37-40 before the onset (Fig. 1b) for Terms 1, 2, and 3 (Fig. 5). It was confirmed that the coherent anomalies appeared along the isotherms of $28-29^{\circ} \mathrm{C}$ in SST near the northern region of the WNPSM, that is, positive in Term 1 (Fig. 5a), negative in Term 2 (Fig. 5b), and positive in Term 3 (Fig. 5c). These anomalies might induce the anomalous atmospheric circulation change at the onset in and around the region of the WNPSM (Figs. 3, 4). Note that these anomalies were weakly correlated with the SSTAs below, although Lau et al. (1997) pointed out that the convective activity was quite sensitive to SSTAs near $29^{\circ} \mathrm{C}$.

To find a more robust relationship between SSTA and the precursors, we examined the local correlation between the SST, trade wind inversion (TWI), and temperature lapse rate in the PBL $\left(\Gamma_{\mathrm{PBL}}\right)$ in the WNP (Fig. 6). Since the OPI of the WNPSM occurs within a small time range around five days or so (Fig. 1b), this work focused on the small spatial scale or local phenomenon, that is, static or convective instability. The strength of the TWI was evaluated by the vertical p-velocity at $850 \mathrm{hPa}\left(\omega_{850}\right)$, since TWI is representative of subsidence inversion appearing around the top of the PBL. $\Gamma_{\mathrm{PBL}}$ is likely sensitive to SST as the definition is based on temperature without humidity, unlike $-d \theta e /\left.d z\right|_{\mathrm{PBL}}$, and Kato et al. (2007) pointed out that the $\Gamma_{\mathrm{PBL}}$ is a key parameter to determine the height of cumulus clouds, i.e., the strength of cumulus

(a)(SST, $\left.\omega_{850}, \operatorname{Corr}(\mathrm{SST},-\mathrm{dT} / \mathrm{dz})\right)$ before onset

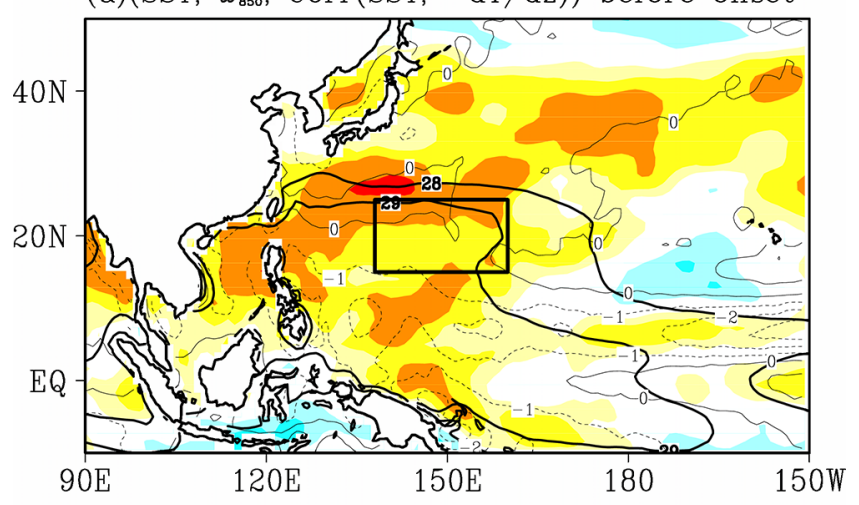

(b) (SST, $\left.\omega_{850}, \operatorname{Corr}(\mathrm{SST},-\mathrm{dT} / \mathrm{dz})\right)$ after onset

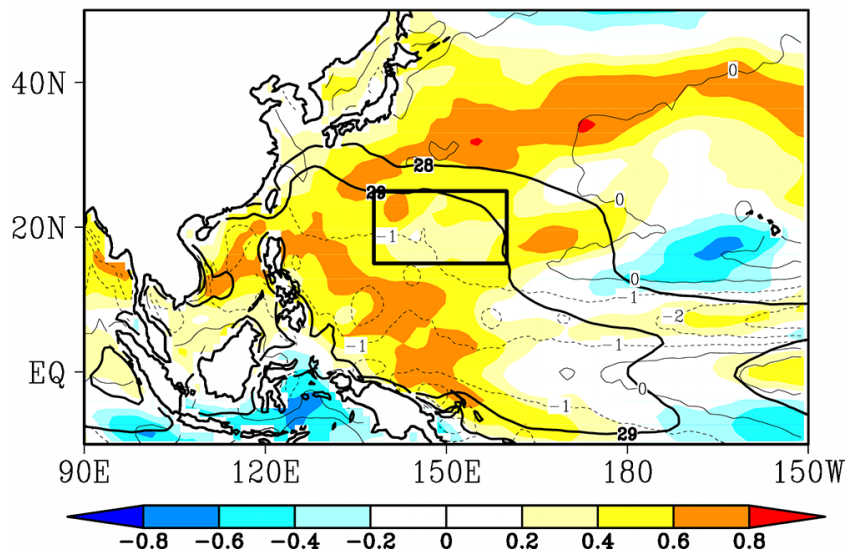

Fig. 6 Local correlations between SST and $\Gamma_{\mathrm{PBL}}$ (color) in (a) P37-40 before the onset of the WNPSM and in (b) P41-44 after the onset (Fig. 1b). The common color scale is at the bottom, and correlations larger than $\pm 0.35 \mid$ are significant at the $95 \%$ level. Thick solid lines indicate $28^{\circ} \mathrm{C}$ and $29^{\circ} \mathrm{C}$ in climatological mean SST, while thin contours exhibit the climatological mean $\omega_{850}\left(\mathrm{~Pa} \mathrm{~s}^{-1}\right)$, where ascent is expressed as negative with dotted contours. The contour interval is $1.0 \mathrm{~Pa} \mathrm{~s}^{-1}$. convection. It is suggested that before the onset of the WNPSM, $\Gamma_{\text {PBL }}$ was coherently modified with decadal-scale SSTAs under the TWI in the tropical WNP and led the DSM in the following OPI.

Figure 6 shows the fields of climatological $\omega_{850}$ (thin contour) and SST (thick contour; only $28^{\circ} \mathrm{C}$ and $29^{\circ} \mathrm{C}$ ), and the correlation coefficients between SST and $\Gamma_{\mathrm{PBL}}$ (color) around the onset of the WNPSM. Before onset (Fig. 6a), a significant positive correlation of over 0.6 appeared under the TWI along the $28^{\circ} \mathrm{C}$ and $29^{\circ} \mathrm{C}$ contours near the northern region of the WNPSM. This positive correlation indicates that $\Gamma_{\mathrm{PBL}}$ is large when positive SSTAs appear. This larger $\Gamma_{\mathrm{PBL}}$ further induces the stronger cumulus convection (Kato et al. 2007) resulting in larger precipitation or larger OPI than usual.

This tendency is also observed around the northern Philippines to the west of the region of the WNPSM, which may lead the anomalous convection around the onset of the WNPSM (Figs. 3, 4) with SSTAs in the region (Fig. 5). Once the WNPSM begins (Fig. $6 b)$, the TWI and correlation weaken, particularly in the northern and western regions of the WNPSM. In the central region of the WNPSM, cumulus convection may have partly contributed to the weakening of the TWI even before the onset (Fig. 6a), although the correlation of $\Gamma_{\mathrm{PBL}}$ with SST is still significantly large and positive. In the region around $\left(170^{\circ} \mathrm{W}, 15^{\circ} \mathrm{N}\right)$ with negative correlation, the adiabatic heating by descent could be larger than the concurrent surface heating by downward shortwave radiation. The accumulated instability under the TWI before the onset seems to control the largeness of OPI.

The date of onset of the WNPSM centers on a specific date, July 20, as with other monsoons. This phase locking was confirmed by examining nine figures similar to Fig. 1a, but for Terms 1,2 , and 3 , having the lags of $-1,0$, and +1 pentads (not shown). The end date of the Baiu season is also centered on July 21 in Japan with the standard deviation of 9 days for 1979-2008 (Tomita et al. 2011). The DSM for the onset date of the WNPSM is relatively small, but not zero. The two candidates for the disturbance leading to the onset, which are listed in the introduction, seem to have strong phase locking.

The length of the time series used by Ueda et al. (1995; 19801989 ) is different from that used by Suzuki and Hoskins (2009; 1979-2001) (Fig. 2). Half of the former overlaps with Term 1, while the latter involves both Terms 1 and 2. These climatologies, or decadal-scale means, are obviously different, which appears to be a fundamental factor to the difference in findings between the two studies. In fact, Ueda et al. (1995) emphasized the PJ-like circulation as the main effect inducing the end of the Baiu season near Japan (Fig. 1), whereas Suzuki and Hoskins (2009) put emphasis on both the PJ-like circulation and the atmospheric circulation in and around the Sea of Japan, related to a Rossby wave train propagating over the Eurasian continent. These differences can be clearly seen in Figs. 4a, b.

\section{Summary}

Differences in the findings of Ueda et al. (1995) and Suzuki and Hoskins (2009) motivated this work, which aimed to explain those differences. It was hypothesized that there was DSM in atmospheric circulation change at the onset of the WNPSM (July 20; Fig. 1). This hypothesis was tested by diagnosing JRA and GPCP datasets from 1979 to 2010 (32 years). The components of DSM with periods longer than 11 years were extracted using harmonic analysis that was applied to the detrended time series of the OPI in the WNPSM (Fig. 2). The terms and signs of DSM were determined based on this smoothed time series, i.e., 19851993 was positive (Term 1), 1994-2000 was negative (Term 2), and 2001-2007 was positive (Term 3) (Fig. 2).

Term 1 was characterized by larger OPI than usual, stronger PJ-like circulation change in the WNP, and positive SSTAs in the northern region of the WNPSM near the contours of $28-29^{\circ} \mathrm{C} \mathrm{SST}$ before onset, where the anomalies in $\Gamma_{\mathrm{PBL}}$ and $-d \theta e /\left.d z\right|_{\mathrm{PBL}}$ were both positive. Term 2 is distinguished by the small OPI, southwestward extension of the WNPSM, and a wave train emanating 
from the Philippines towards western North America. In this term, the SSTAs were negative in the northern region of the WNPSM before onset with negative anomalies in $\Gamma_{\mathrm{PBL}}$ and $-d \theta e /\left.d z\right|_{\mathrm{PBL}}$. These were effective in suppressing the OPI. The anomalous oceanic and atmospheric circulations in Term 3 were similar to those in Term 2 but with opposite signs. The spatial patterns of SSTAs in these three terms were somewhat similar to those of the Pacific decadal oscillation (Mantua and Hare 2002).

The WNPSM occurs in a region where the mean SST is around $29^{\circ} \mathrm{C}$, and where the SST variation sensitively controls local convection through the modification of $\Gamma_{\mathrm{PBL}}$ or $-d \theta e /\left.d z\right|_{\mathrm{PBL}}$ under the TWI. That is, the OPI of the WNPSM is sensitive to the local SST variation. On the other hand, the onset date has strong phase locking with so-called onset disturbances, such as the northward movement of summertime ISO (Wu and Wang 2000) or westward propagation of upper cold lows from the mid-Pacific (Sato et al. 2005). These disturbances trigger the onset of the WNPSM during the gradual weakening of the TWI concurrent with a seasonal northward shift of the subtropical Pacific High in the WNP.

However, many issues relating to the DSM of the WNPSM still remain to be investigated, for example, the total precipitation during the WNPSM, the change in distribution pattern of the precipitation, the length of WNPSM, and so forth.

\section{Acknowledgments}

This work was performed with the support of the Research Institute for Global Change of the Japan Agency for Marine-Earth Science and Technology (JAMSTEC) and Grants-in-Aid for Scientific Research $(22106005,25287125)$ from the Ministry of Education, Culture, Sports, Science and Technology (MEXT) of Japan.

\section{References}

Adler, R. F., J. Susskind, G. J. Huffman, D. Bolvin, E. Nelkin, A. Chang, R. Ferraro, A. Gruber, P.-P. Xie, J. Janowiak, B. Rudolf, U. Schneider, S. Curtis, and P. Arkin, 2003: The Version-2 Global Precipitation Climatology Project (GPCP) monthly precipitation analysis (1979-Present). J. Hydrometeor., 4, 1147-1167.

Chou, C., J.-Y. Tu, and J.-Y. Yu, 2003: Interannual variability of the western North Pacific summer monsoon: Differences between ENSO and non-ENSO years. J. Climate, 16, 22752287.

Kato, T., S. Hayashi, and M. Yoshizaki, 2007: Statistical study on cloud top heights of cumulonimbi thermodynamically estimated from objective analysis data during the Baiu season. $J$. Meteor. Soc. Japan, 85, 529-557.

Lau, K.-M., H.-T. Wu, and S. Bony, 1997: The role of large-scale atmospheric circulation in the relationship between tropical convection and sea surface temperature. J. Climate, 10, 381392.

Mantua, N. J., and S. R. Hare, 2002: The Pacific decadal oscillation. J. Oceanogr., 58, 35-44.

Nitta, T., 1989: Global features of the Pacific-Japan oscillation. Meteorol. Atmos. Phys., 41, 5-12.

Onogi, K., J. Tsutsui, H. Koide, M. Sakamoto, S. Kobayashi, H. Hatsushika, T. Matsumoto, N. Yamazaki, H. Kamahori, K. Takahashi, S. Kadokura, K. Wada, K. Kato, R. Oyama, T. Ose, N. Mannoji, and R. Taira, 2007: The JRA-25 Reanalysis. J. Meteor. Soc. Japan, 85, 369-432.

Sato, N., K. Sakamoto, and M. Takahashi, 2005: An air mass with high potential vorticity preceding the formation of the Marcus Convergence Zone. Geophys. Res. Lett., 32, L17801, doi:10.1029/2005GL023572.

Suzuki, S., and B. Hoskins, 2009: The large-scale circulation change at the end of the Baiu season in Japan as seen in ERA40 data. J. Meteor. Soc. Japan, 87, 83-99.

Takaya, K., and H. Nakamura, 2001: A formulation of a phase-independent wave-activity flux for stationary and migratory quasigeostrophic eddies on a zonally varying basic flow. $J$. Atmos. Sci., 58, 608-627.

Tomita, T., T. Yamaura, and T. Hashimoto, 2011: Interannual variability of the Baiu season near Japan evaluated from the equivalent potential temperature. J. Meteor. Soc. Japan, 89, 517-537.

Ueda, H., T. Yasunari, and R. Kawamura, 1995: Abrupt seasonal change of large-scale convective activity over the western Pacific in the northern summer. J. Meteor. Soc. Japan, 73, 795-809.

Wang, B., and LinHo, 2002: Rainy season of the Asian-Pacific summer monsoon. J. Climate, 15, 386-398.

Wu, R., 2002: Processes for the northeastward advance of the summer monsoon over the western North Pacific. J. Meteor. Soc. Japan, 80, 67-83.

Wu, R., and B. Wang, 2000: Interannual variability of summer monsoon onset over the western North Pacific and the underlying processes. J. Climate, 13, 2483-2501.

Wu, R., and B. Wang, 2001: Multi-stage onset of the summer monsoon over the western North Pacific. Climate Dyn., 17, $277-289$.

Manuscript received 14 August 2013, accepted 1 October 2013

SOLA: http://www.jstage.jst.go.jp/browse/sola/ 